\title{
Photosynthetic Responses of Giant Granadilla (Passiflora quadrangularis L.) to Salinity
}

\author{
Yasmina Zozor and Thomas E. Marler ${ }^{1}$ \\ Fairchild Tropical Garden, 11935 Old Cutler Road, Miami, FL 33156
}

Additional index words. chlorophyll fluorescence, net $\mathrm{CO}_{2}$ assimilation, quantum yield

The giant granadilla is distributed throughout the tropics and may deserve wider use as a commercial crop (Martin et al., 1987). Knowledge of the factors that affect photosynthesis of tropical species is a prerequisite for successful cultivation (Possingham, 1986). Utsunomiya and Shigenaga (1988) observed a reduction in giant granadilla shoot growth and stomatal conductance when plants were irrigated with $\mathrm{NaCl}$ levels up to $\approx 4.5 \mathrm{dS} \cdot \mathrm{m}^{-1}$. Salinity effects on plant growth and yield depend in part on factors that influence the rate of C gain (Yeo, 1983). Understanding the influence of salinity on photosynthesis of this species may thus be of benefit in managing fruit production in areas with salinity problems. The objective of this study was to determine the effects of substrate salinity on the photosynthetic process of giant granadilla.

Giant granadilla cuttings from a single clone were taken on 6 July 1990 and rooted in perlite under intermittent mist. The plants were potted on 1 Aug. in a medium of equal parts of perlite, sand, peat, and bark chips (by volume) in 2.6-liter containers and grown on raised benches under glasshouse conditions (50\% ambient light by whitewash). A topdressing of $6 \mathrm{~g}$ complete granular fertilizer was applied every 8 weeks. All plants were pruned to two nodes on 6 Dec. and spaced $30 \mathrm{~cm}$ in a diamond pattern. Regrowth of a single shoot was trained to 90$\mathrm{cm}$ bamboo stakes. When the leaves near the top of the stakes were fully expanded, uniform plants were chosen and the growth above the stakes was pruned. The gas exchange of the three terminal leaves of each plant did not differ based on preliminary data obtained before the salinity treatment. These leaves were chosen at random on each plant for all gas exchange measurements throughout the study.

Received for publication 24 Dec. 1991. Accepted for publication 1 July 1992 . The cost of publishing this paper was defrayed in part by the payment of page charges. Under postal regulations, this paper therefore must be hereby marked advertisement solely to indicate this fact.

${ }^{1}$ To whom reprint requests should be addressed. Present address: College of Agriculture \& Life Sciences, Univ. of Guam, UOG Station, Mangilao, Guam 96923.
The salinity treatments were begun on 23 Jan. 1991 by increasing irrigation water 1 $\mathrm{dS} \cdot \mathrm{m}^{-1}$ every other day until $4 \mathrm{dS} \cdot \mathrm{m}^{-1}$ was reached on 29 Jan. The solution was made by dissolving sea salt in collected rainwater and had an osmotic potential of $-0.18 \mathrm{MPa}$. The control plants were irrigated with rainwater. Irrigation was applied by hand every other day to obtain $\approx 25 \%$ leaching fraction and was continued through 30 Mar. (day 67). A completely randomized design was used with six plants per treatment. Maxima and minima during the 67 days averaged $33 \pm$ $1 \mathrm{C}$ and $19 \pm 1 \mathrm{C}$. Maximum and minimum relative humidity averaged $91 \% \pm 1 \%$ and $47 \% \pm 2 \%$.

Net $\mathrm{CO}_{2}$ assimilation (A) was measured on 23 Jan. and every 3 to 7 days until 19 Mar. (day 56) using a LI-COR 6250 gas analyzer (LI-COR, Lincoln, Neb.). Three 10sec $\mathrm{CO}_{2}$ depletion periods were recorded on $15 \mathrm{~cm}^{2}$ of one leaf from each plant during late morning on each measurement day under ambient conditions of the greenhouse. A decline in $\mathrm{A}$ of treated plants occurred by day 10 to $\approx 70 \%$ of control plants. This decline continued until day 56 , when A of treated plants averaged $\approx 50 \%$ of control plants.

A second study was conducted concomitantly to determine the influence of salinity on chlorophyll fluorescence and the response of A to light. Four plants per treatment were arranged in a completely randomized design and received the treatment described. Light response curves were measured on two plants of each treatment on $19 \mathrm{Feb}$. and the other two plants on $21 \mathrm{Feb}$. (days 28 and 30). The light level was lowered between measurements of A by placing nylon screening in layers over the cuvette. Apparent quantum yield was calculated as the initial slope of the response curve $\left(<150 \mu \mathrm{mol} \cdot \mathrm{m}^{-2} \cdot \mathrm{s}^{-1}\right)$. Slopes for each of the four replications of each treatment were found to estimate the same population according to analysis of covariance test for homogeneity. The data were then pooled within treatments, and the slopes from each treatment were tested for homogeneity. Data from the two highest values in the light-saturated portion of the response curve were pooled to estimate maximum A, and subjected to analysis of variance (ANOVA). Salinity caused a reduction of light-saturated $\mathrm{A}$ and of apparent quantum yield to $\approx 50 \%$ of control values (Table 1 ).

The plants were transferred from the glasshouse to a darkroom on 30 Mar. (day 67) at $1200 \mathrm{HR}$ and were allowed to adapt to darkness for $15 \mathrm{~min}$. Instantaneous and maximal fluorescences were measured on the adaxial side of two laminae per plant using a Brancker SF-30 fluorometer (Richard Brancker Research, Ottawa). Variable fluorescence was calculated as the difference between maximal and instantaneous fluorescence, and fluorescence ratio was calculated by division of variable by maximal fluorescence. Data were subjected to ANOVA. Salinity reduced the fluorescence ratio of giant granadilla leaves to $\approx 60 \%$ of control values (Table 1), indicating that salinity stress increased photoinhibitory damage (Bolhar-Nordenkampf et al., 1989).

In summary, A of giant granadilla was reduced within 2 weeks following irrigation with saline water. Salinity stress decreased the efficiency of light energy use and induced an increase in photoinhibitory damage.

\section{Literature Cited}

Bolhar-Nordenkampf, H.R., S.P. Long, N.R. Baker, G. Oquist, U. Schreiber, and E.G. Lechner. 1989. Chlorophyll fluorescence as a probe of the photosynthetic competence of leaves in the field: A review of current instrumentation. Functional Ecol. 3:497-514.

Martin, F.W., C.W. Campbell, and R.M. Ruberte. 1987. Perennial edible fruits of the tropics. U.S. Dept. Agr.-Agr. Res. Serv. Agr. Hndbk. 642, Washington, D.C

Possingham, J.V. 1986. Impact of physiological research on the productivity of tropical and subtropical fruit trees. Acta Hort. 175:17-25.

Utsunomiya, N. and S. Shigenaga. 1988. Effect of $\mathrm{NaCl}$ on the growth and salt accumulation in young plants of giant granadilla (Passiflora quadrangularis L.) and yellow passion fruit (Passiflora edulis Sims forma flavicarpa Degener). Jpn. J. Trop. Agr. 32(3):147-153.

Yeo, A.R. 1983. Salinity resistance: Physiologies and prices. Physiol. Plant. 58:214-222.

Table 1. Influence of irrigating giant granadilla with a rainwater control or a $4-\mathrm{dS} \cdot \mathrm{m}^{-1}$ solution of sea salt on maximal net $\mathrm{CO}_{2}$ assimilation, apparent quantum yield, and fluorescence ratio.

\begin{tabular}{lccc}
\hline \hline Salinity & $\begin{array}{c}\text { Net } \mathrm{CO}_{2} \text { assimilation } \\
\left(\mu \mathrm{mol} \mathrm{CO} \mathrm{CO}_{2} \text { per sec) }\right.\end{array}$ & $\begin{array}{c}\text { Quantum yield } \\
(\mu \mathrm{mol} \mathrm{CO} / \mu \mathrm{mol} \text { photons })\end{array}$ & $\begin{array}{c}\text { Fluorescence } \\
\text { ratio }\end{array}$ \\
\hline $\mathrm{No}$ & 10.89 & 0.033 & 0.52 \\
Yes & $5.83^{*}$ & $0.018^{*}$ & $0.33^{*}$ \\
\hline
\end{tabular}

*Significant at $P=0.01$. 